\title{
Predicting financial distress of companies listed on the JSE - A comparison of techniques
}

\author{
G.H. Muller \\ University of Stellenbosch Business School, \\ PO Box 610, Bellville 7535, Republic of South Africa \\ B.W. Steyn-Bruwer* \\ Department of Accounting, University of Stellenbosch, \\ Stellenbosch 7600, Republic of South Africa \\ Bws1@sun.ac.za \\ W.D. Hamman \\ University of Stellenbosch Business School, \\ PO Box 610, Bellville 7535, Republic of South Africa \\ Received November 2008
}

\begin{abstract}
In 2006, Steyn-Bruwer and Hamman highlighted several deficiencies in previous research which investigated the prediction of corporate failure (or financial distress) of companies. In their research, Steyn-Bruwer and Hamman made use of the population of companies for the period under review and not only a sample of bankrupt versus successful companies. Here the sample of bankrupt versus successful companies is considered as two extremes on the continuum of financial condition, while the population is considered as the entire continuum of financial condition.
\end{abstract}

The main objective of this research, which was based on the above-mentioned authors' work, was to test whether some modelling techniques would in fact provide better prediction accuracies than other modelling techniques. The different modelling techniques considered were: Multiple discriminant analysis (MDA), Recursive partitioning (RP), Logit analysis (LA) and Neural networks (NN).

From the literature survey it was evident that existing literature did not readily consider the number of Type I and Type II errors made. As such, this study introduces a novel concept (not seen in other research) called the "Normalised Cost of Failure" (NCF) which takes cognisance of the fact that a Type I error typically costs 20 to 38 times that of a Type II error.

In terms of the main research objective, the results show that different analysis techniques definitely produce different predictive accuracies. Here, the MDA and RP techniques correctly predict the most "failed" companies, and consequently have the lowest NCF; while the LA and NN techniques provide the best overall predictive accuracy.

*To whom all correspondence should be addressed.

\section{Introduction}

Since the demise of Arthur Andersen, Enron and WorldCom, global economies are becoming increasingly cautious of signs of corporate demise and bankruptcy. It was the collapse of these companies that resulted in enormous losses to both investors and lending institutions involved with these companies. As a result, many organisations around the world have concentrated on corporate ethics and governance with a view to minimise the risks of corporate financial distress. Although corporate ethics and governance have created a platform to prevent financial distress, the early prediction of distress is essential for investors or lending institutions who intend to protect their financial investments.

As a consequence, modelling, prediction and classification of companies to determine whether they are potential candidates for financial distress have become key topics of debate and detailed research. Corporate bankruptcy was first modelled, classified and predicted by Beaver in 1966 (Beaver, 1966). According to Deakin (1972), Beaver defined financial distress as bankruptcy, insolvency, liquidation for the benefit of a creditor, firms which defaulted on loan obligations or firms that missed preferred dividend payments. Beaver's technique accurately classified $78 \%$ of the sample companies five years prior to failure. The research completed by Beaver concluded that the cash flow to debt ratio was the single best indicator of bankruptcy.

To date there have been numerous further attempts at predicting bankruptcy or financial distress of companies using many different techniques. However, there is little consensus on (1) which technique provides the most accurate results, (2) what input variables to use and (3) on the definition of financial distress itself. 


\section{Definition of financial distress}

One of the major concerns in this field of research is the lack of consensus on the definition of corporate failure or financial distress. On the one end of the continuum, authors have strictly used bankruptcy as the definition. However, other researchers define financial distress as mergers, absorptions, delisting or liquidations or major structural changes to the company.

Cybinski (2001) explains that "failed" and "non-failed" firms do not lie in separate boxes, but rather lie on a continuum of "failed" and "non-failed". In reality there is not a cut-off point between "failed" and "non-failed" firms, but rather an overlap or grey area between the two. It is in this grey area that prediction of financial distress is so difficult.

Furthermore, Balcaen and Ooghe (2006) mention that "corporate failure is not a well defined dichotomy". It appears from most research that the criterion for failure is chosen arbitrarily and could either mean judicial bankruptcy or financial distress. It must be noted that this has serious implications in the repeatability and generalisation of results.

According to the Wikipedia (2008), the definition of financial distress is "a term in corporate finance used to indicate a condition when promises to creditors of a company are broken or honoured with difficulty. Sometimes financial distress can lead to bankruptcy”.

In most studies to date (Foster, 1986: 535), filing for bankruptcy has been the most commonly used criterion for financial distress. Foster (1986) indicates that filing for bankruptcy is a legal event which is heavily influenced by the actions of bankers and or other creditors. He continues to define the term financial distress to mean "...severe liquidity problems that cannot be resolved without a sizable rescaling of the entities' operations or structure”.

It must be noted that companies may file for bankruptcy even though their performance and financial ratios do not predict this (Balcaen \& Ooghe, 2006). On the other hand, some companies may only just be surviving corporate failure, but are actually classified as a "non-failed" company. Some companies may strategically file for bankruptcy to eliminate rising debts. Other companies may file for bankruptcy due to "acts of God" and may be forced into bankruptcy even though their previous financial results were excellent.

It is also worth noting that in different countries the occurrence of liquidation may differ. Kuruppu, Laswad and Oyelere (2003) indicated that in creditor orientated countries such as UK, Germany, Australia and New Zealand, liquidation is more likely to be the outcome of insolvency. Here a creditor can obtain control of the company and have the legal right to recover their debt despite the fact that it results in the liquidation of the company. In the case of debtor orientated countries such as the USA, the USA bankruptcy code is designed to keep companies as a going concern. Kuruppu et al. (2003) list the following alternative definitions of corporate failure: large losses disproportionate to assets; share exchange delisting; companies in the process of liquidation; an arrangement with creditors; negative share returns; and receipt of a going concern qualification.

For the purpose of this research, financial distress is defined (Steyn-Bruwer \& Hamman, 2006) as the situation when a company cannot continue to exist in its current form and therefore includes: bankruptcy, delisting or a major organisational restructuring. For the purposes of this research, the terminology "failed" and "non-failed" will be used to classify the respective companies.

\section{Overview of principal research in the field of failure prediction}

In 2006, Aziz and Humayon (2006: 18) compiled an extensive literature review on 46 articles reporting 89 empirical studies of predicting corporate bankruptcy. The authors analysed the accuracies of three different types of predictive models: (1) statistical models, (2) artificial intelligent expert system (AIES) models, and (3) theoretical models. Of the reviewed literature, $64 \%$ of all authors used statistical techniques, 25\% of the authors used AIES models, and $11 \%$ of the authors used theoretical models. The different categories were comprised as follows:

- $\quad$ Statistical model category: This category comprised the MDA and LA techniques where the overall predictive accuracy was $84 \%$.

- $\quad$ AIES models: This category included RP and NN, where overall accuracy was $88 \%$.

- $\quad$ Theoretical models: This category primarily consists of entropy theory where the accuracy was calculated as $85 \%$.

\section{Multiple discriminant analysis}

Altman (1968) developed his classic multivariate insolvency model based on Multiple discriminant analysis (MDA). MDA is based on the development of a linear equation which provides an overall score used to predict whether the subject lies in either of the two (or more) groups. According to Rees (1995: 302) “the resulting equation combines and then weighs the variables in such a way as to maximise its ability to discriminate between groups". A typical MDA equation is given as:

$\mathrm{Z}=\mathrm{b}_{1} \bullet \mathrm{X}_{1}+\mathrm{b}_{2} \bullet \mathrm{X}_{2}+\mathrm{b}_{3} \bullet \mathrm{X}_{3}+\ldots+\mathrm{b}_{\mathrm{n}} \bullet \mathrm{X}_{\mathrm{n}}$

where:

- $\quad \mathrm{Z}$ is the outcome of the MDA equation

- $b_{1}$ to $b_{n}$ are the discriminant coefficients of the MDA equation 
- $\quad \mathrm{X}_{1}$ to $\mathrm{X}_{\mathrm{n}}$ are independent variables for each individual sample

The result from the above-mentioned equation, $\mathrm{Z}$, is a cutoff value where each sample is classified into a group depending on whether the resultant score of $\mathrm{Z}$ is greater than or smaller than a predetermined cut-off value. In terms of predicting financial distress, companies are classified as "failed" or "non-failed" based on the overall score of the discriminant function. In this case, if the Z-score is less than the cut-off, the firm is classified as "failed", while if the score is greater than the cut-off then the firm is classified as "non-failed".

In the initial paper of Altman the bankrupt samples were companies that filed for bankruptcy under the National Bankruptcy Act from 1946 to 1965 (Altman, 2000). In the model, the Z-score indicator provided a forecast of whether the company would enter into distress within a two year period, using a cut-off value of 2,67, where the following equation was used to predict financial distress:

$$
\begin{aligned}
& \mathrm{Z}=1,2 \bullet \mathrm{X} 1+1,4 \bullet \mathrm{X} 2+3,3 \bullet \mathrm{X} 3+ \\
& 0,6 \bullet \mathrm{X} 4+1,0 \bullet \mathrm{X} 5
\end{aligned}
$$

where each coefficient is defined as:

- $\quad \mathrm{X} 1$ is working capital / total assets ratio

- $\mathrm{X} 2$ is retained earnings / total assets ratio

- $\mathrm{X} 3$ is earnings before interest and taxes / total assets ratio

- $\quad \mathrm{X} 4$ is market value of equity / book value of total debt ratio

- $\quad \mathrm{X} 5$ is sales / total assets ratio

The same author (Altman, 2000) documented the results of tests that he conducted on 110 companies that went bankrupt between 1976 and 1995. In the same paper he also documented the results of a further 120 companies that went bankrupt between 1997 and 1999. After the last battery of tests, the author recommended a lower Z-score cut-off of 1,81 and treating Z-scores between 1,81 and 2,67 as an "ignorance zone" where the company in question has a high probability of becoming bankrupt.

Two important conclusions were provided by Altman (1993: 201): Firstly, the observed ratios show a deteriorating trend as bankruptcy approaches, and secondly the most serious change in the majority of these ratios occurred between the second and third years prior to bankruptcy. Altman suggested that the Z-score model is an accurate forecaster of failure for up to two years prior to failure, but the accuracy diminishes as the lead time increases.

The Altman Z-score model and MDA has arguably been the most prolific tool for predicting bankruptcy. However, as with most methods there are criticisms. One of the criticisms (Grice \& Ingram, 2001: 54) is that the hold-out sample accuracy rates in Altman's and other studies are potentially upwardly biased. This means that the hold-out sample accuracy rates are higher than what users would expect when they apply the models to a different sample of companies.

In 1972 Deakin (1972) used MDA to predict business failure in 11 "failed" and 23 "non-failed" companies. Deakin's definition of failure was when companies experience bankruptcy, insolvency or liquidation. He achieved an accuracy of $87 \%$ (one year before failure), 90\% (two years before failure) and 82\% (three years before failure).

In 1977, Altman, Haldeman and Narayanan (1977) developed the ZETA score which was essentially the second generation of the original Z-score model of Altman. The ZETA model is regarded by Altman et al. (1977: 51), as a more accurate and relevant failure prediction model which is specifically targeted at credit worthiness analysis of firms for financial and non-financial institutions.

Taffler (1982: 342) adapted the Z-score model of Altman by utilising the sum of four weighted ratios. The equation (Agarwal \& Taffler, 2007: 9) describing the Z-score system is given as:

$Z=2,18 \bullet X_{1}+2,50 \bullet X_{2}-10,68 \bullet X_{3}+0,0289 \bullet X_{4} \ldots$

where:

- $\quad \mathrm{X} 1$ is profit before tax / average current liabilities

- $\quad \mathrm{X} 2$ is current assets / total liabilities

- $\quad \mathrm{X} 3$ is current liabilities / total assets

- $\mathrm{X} 4$ is the credit interval

Here companies with a negative Z-score were considered as financially distressed and in danger of failure while those with a positive Z-score were classified as solvent.

\section{Studies using Logit analysis}

Ohlson (1980) researched the probabilistic prediction of bankruptcy using Logit analysis (LA). The equation defining LA is:

$\mathrm{P}(\mathrm{x})=1 /\left[1+\mathrm{e}^{-(\mathrm{bo}+\mathrm{b} 1 \bullet \mathrm{x} 1+\mathrm{b} 2 \bullet \mathrm{x} 2++\mathrm{bn} \bullet \mathrm{Xn})}\right]$

where:

- $\quad \mathrm{P}(\mathrm{x})$ is the probability of failure for a firm

- $b_{\mathrm{i}}$ is the coefficient for each independent variable

- $\quad \mathrm{X}_{\mathrm{j}}$ is the actual value for each independent variable

The application of LA requires four steps: (1) calculate a series of financial ratios, (2) multiply each ratio with its corresponding coefficient, (3) sum the result of each coefficient to form a new variable $y$, and (4) calculate the probability of financial distress for a company as $1 /\left(1+\mathrm{e}^{-\mathrm{y}}\right)$. Here the independent variables with a negative coefficient increase the probability of financial distress due to the fact that they reduce $\mathrm{e}^{-\mathrm{y}}$ toward zero, with the result 
that the financial distress (probability function) approaches $1 / 1$, or 100 percent. Likewise, the independent variables with a positive coefficient decrease the probability of financial distress (Ohlson, 1980: 110).

According to Balcaen and Ooghe (2006: 69), the advantage of LA is that firstly it does not rely on the assumption of normality for the sample data and secondly it does not require an equal dispersion matrix. In general, LA is far less demanding than MDA analysis.

In 1980, Ohlson was able to predict failure of companies based on the probability of financial distress for one year prior to failure and two years prior to failure, to an accuracy of $96,1 \%$ and $95,5 \%$ respectively.

Zavgren (1985) also used LA to predict financial distress and argued that one of the advantages of the technique is that it overcomes the issues of non-normality of the sample. She argued that models which generated a probability of failure were more useful than those that produced a dichotomous classification as with the MDA.

\section{Recursive partitioning}

Recursive partitioning (RP) (or Decision trees) can also be used to classify or predict membership to two or more groups of dependent variables based on more than one independent variable. According to Statistica ${ }^{\mathrm{TM}}$ (2008), RP is a hierarchy of questions which leads to a final decision depending on the answer of all the previous questions. During the process, a tree is modelled, where, at each split in the tree, all the independent variables are tested to find (1) the independent variables that discriminate the best between "failed" and non-failed" companies and (2) the value of this specific variable that will result in the most accurate classification at this split.

It is important to note that in MDA, the decisions are simultaneous while in RP the decisions are hierarchical, which is one of RP's most fundamental features. Another distinctive characteristic of RP is its flexibility, since it does not require any assumptions about the distribution of the measurements in each group. Measurements can be categorical, discrete numeric, or continuous.

During 2006, in a South African study, Steyn-Bruwer and Hamman (2006) used RP to predict financial distress on industrial companies on the JSE. In their study, some of the shortcomings in previous research on failure prediction were addressed. The deficiencies were addressed as follows:

- $\quad$ Brute empirism was avoided by focussing on cash flow ratios in combination with certain accrual ratios.

- Failure was not only defined as the extreme, bankruptcy, but as any condition where the company cannot exist in future in its current form, including delistings as well as major structural changes.
- $\quad$ By using the population of listed industrial companies during the period under review, the grey area inbetween "successful" and "bankrupt" was included in developing the models.

- The use of the population avoided the problem in previous studies of equal samples of "failed" and "nonfailed" companies resulting in over or understatement of classification accuracy.

- $\quad$ Every model was tested by means of an independent sample. The focus in reporting therefore was on the prediction accuracy of the testing sample and not the classification accuracy of the learning sample, which for obvious reasons will always be reasonably good.

\section{Neural networks}

The Neural networks (NN) fundamentally maps inputs to the outputs using layers and neurons to create a "complex learned algorithm”. Essentially the parameters (coefficients and weights) of layer/s are trained for the duration of historical data, based on known inputs and outputs. Each of the layers comprises many neurons connected to neurons in the preceding and subsequent layers. The value of each neuron is transferred through the connections to other neurons in the network. A second data set is used with these predetermined parameters, obtained from training the network, to obtain the relevant output. It is these outputs that are then statistically compared with actual outputs to determine whether there is any correlation between the simulated and actual results. Each $\mathrm{NN}$ has several key components, which will be discussed next.

At the heart of the $\mathrm{NN}$ is the neuron. Each neuron comprises (1) the input, (2) the weight multiplier, (3) the summation function, and (4) the activation function. Each neuron receives a number of inputs (either from original data, or from the output of preceding neurons in the NN). Each input is multiplied by an associated "learned" weight. The sum of the weighted inputs is added to obtain the input into the activation function. If the output of the activation function exceeds a pre-set threshold value, the neuron fires. If not, the neuron does not fire.

Mathematically, the neuron only fires if the following condition is met:

$\mathrm{f}\left(\mathrm{X}_{1} \bullet \mathrm{W}_{1}+\mathrm{X}_{2} \bullet \mathrm{W}_{2}+\ldots+\mathrm{X}_{\mathrm{n}} \bullet \mathrm{W}_{\mathrm{n}}\right)>\mathrm{T}$

where:

- $\quad \mathrm{T}$ is the threshold value

- $\mathrm{W}_{\mathrm{i}}$ is the "learned" weight for each input

- $\mathrm{X}_{\mathrm{i}}$ is the input value from the preceding neuron

This activation function is also known as the transfer function. Figure 1 provides a diagrammatic representation of the artificial neuron (Zirilli, 1997). 


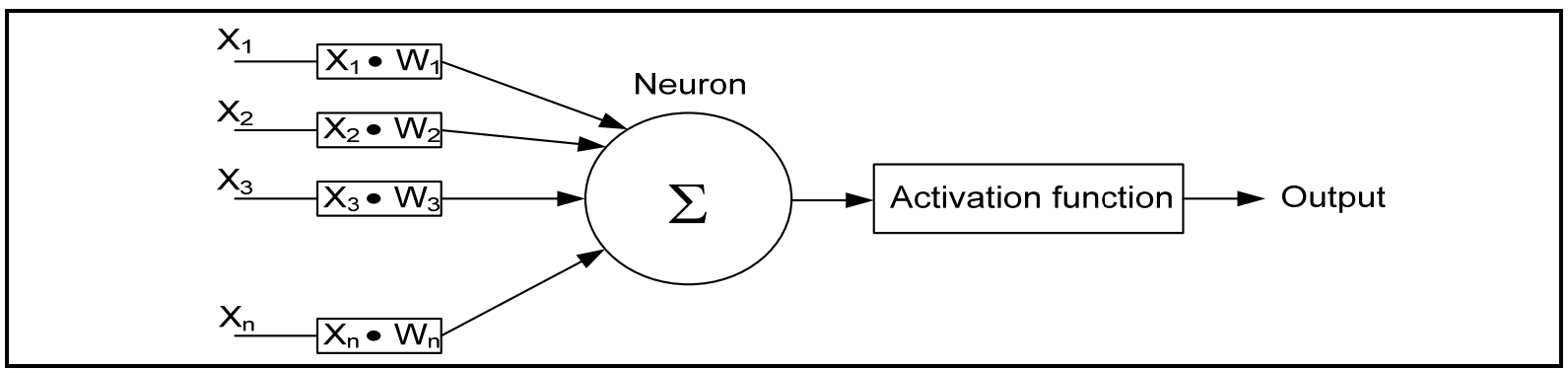

Figure 1: Diagramme representing an artificial neuron (J. Zirilli: 1997)

The NN relies on (1) the weight of the connection, (2) the firing threshold, as well as (3) the activation function or transfer function. However, the non-linearity of the $\mathrm{NN}$ is achieved primarily by the activation or transfer function, which can assume three forms: (1) linear (or ramp), (2) threshold (0 or 1$)$, or (3) sigmoid.

All NN consists of several layers: (1) the input layer, (2) the hidden layer (of which there may be several) and, (3) the output layer. Figure 2 provides an overview of the different NN layers.

These layers have the following functions:

- The function of the input layer of neurons is to feed the input variables into the network without processing any of the input information.
- The function of each hidden layer of neurons is to process the input variables. This is completed by weighting the connection of each input, summing the total of all the inputs, checking whether the total meets the threshold value and applying the activation function. It is the weights between the input and hidden units that determine when each neuron in the hidden layer is active, and by modifying these weights, a hidden layer may fire or not.

- The behaviour of the output layer of neurons is similar to that of the hidden layer where each input is processed as a hidden layer. The hidden and output layer neurons are connected to all of the neurons in the preceding layer.

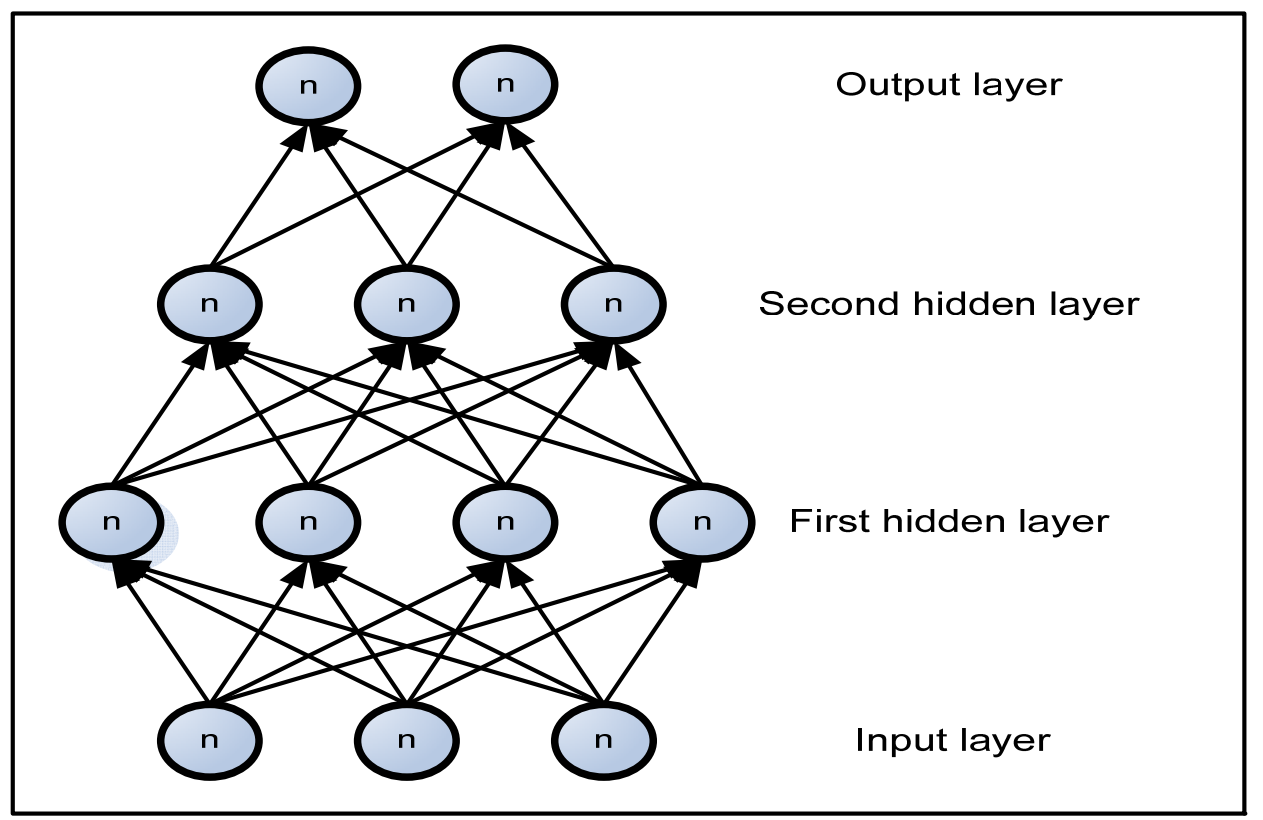

Figure 2: Diagramme representing the different layers in the Neural network

According to Matlab ${ }^{\mathrm{TM}}$ (2007) there are two types of NN training algorithms. These are supervised and unsupervised training, of which supervised is the most common. A description of the different type of algorithms is discussed below:
- In supervised learning, the inputs together with the known/correct outputs are applied to the NN during the training phase, such that the $\mathrm{NN}$ can adjust its weights to match its outputs to the actual outputs. After training is complete, validation of the model occurs where another set of inputs, without the known outputs, is 
applied to the NN. In the case of this research two thirds of the data are used for training, while one third of the data is used to validate the results. Here the predicted outputs from the NN are matched against the actual outputs to determine the accuracy of prediction of the NN. Once the model has been developed with the correct weights, it is ready to be applied on real data. One of the key issues regarding supervised learning is the issue of error convergence (i.e. the minimisation of error between the desired and computed values). The aim of the learning algorithm is to determine a set of weights which minimises the error. The method used in Matlab ${ }^{\mathrm{TM}}$ to minimise the error is the least mean square (LMS) algorithm.

- In unsupervised training, the NN is only provided with inputs (and not the outputs) to calculate the appropriate connection weights.

The two major kinds of NN topologies are feed-forward and feedback topologies:

- In the feed-forward $\mathrm{NN}$, the connections between neurons only occur in the direction from input to output. There are no feedback paths and as a result the speed of the feed-forward NNs is usually very fast. Feed-forward NNs tend to be straight forward networks that associate inputs with outputs and according to the literature are extensively used in pattern recognition.

- $\quad$ Feedback NNs can have signals travelling in both directions by introducing loops in the network. Typically the error signal at the output of the NN is passed back into NN to correct the connecting weights. As such, feedback networks are very powerful, are extremely complicated and consume vast amount of processing power.

Studies comparing the accuracy of several different analysis

In the research of Aziz and Lawson (1989), the authors utilised cash flow information based on the operating cash flow model of Lawson to predict financial distress. The authors used the Z-score model, Zeta score model, LA model and a mixed model to predict financial distress on 49 matched companies between 1973 and 1982. The overall comparative classification and predicative accuracy on the hold-out sample between the Z-score model, Zeta score model, LA model and mixed model were $77,4 \%, 92,8 \%$, $76,3 \%, 82,8 \%$ respectively. The authors argued that operating cash flows were important variables to predict financial distress.

Back, Laitinen, Sere and Wezel (1996) investigated the performance of MDA, LA and NN to 37 randomly selected "failed" and "non-failed" Finnish companies. The authors selected different independent variables for each of the different techniques based on an analysis of variance, stepwise logistic regression and factor analysis. The overall predictive accuracy (one year before failure) for Multiple Discriminant Analyses was 85,1\%, for LA 96,5\%, and for NN 97,3\%.

Pompe and Bilderbeek (2005) defined financial distress as the legal status of bankruptcy where the company had suspended all payments against creditors and subsequently lost all credit. The authors utilised both NN and MDA on 476 bankrupt and 1500 non-bankrupt firms. The data was divided into two equal sections - the training data and the validation data. Based on stepwise selection of variables the overall accuracy prediction for MDA method was $80 \%$ and $76 \%$ for old and young companies respectively, and in the case of $\mathrm{NN}, 81 \%$ and $77 \%$ for old and young companies respectively. Pompe and Bilderbeek also compared their results to that of Beaver's (1966). As with Beaver, these authors concurred that the cash flow to total debt ratio was the strongest single ratio to predict failure.

In South Africa Court and Radloff (1990: 11) used MDA and Logistic regression analysis (LRA) to predict corporate failure on 26 matched companies listed on the JSE between 1965 and 1986. They defined failure as a company which had delisted from the JSE due to poor financial performance and which was later liquidated. Fifteen financial ratios were then reduced to four ratios using factor analysis. Court and Radloff (1990) showed that LRA provided better predictive results than MDA. Here, the overall predictive accuracy of MDA and LRA was 78,5\% and 84,6\% respectively.

In another South African study, Arron and Sandler (1995: 57) used MDA, LA and NN to predict corporate bankruptcy on 28 "failed" and 40 "non-failed" companies listed on the JSE between 1966 and 1993. They reduced the number of financial ratios from 15 initial ratios to six final ratios based on the Wilk's Lambda test. The combined predictive accuracy of the three techniques (comparing "non-failed" companies to "failed" companies one year before failure) was $83,2 \%, 86,8 \%$ and $87,8 \%$ for MDA, LA and NN respectively. The authors concluded that all three techniques were more accurate in predicting "non-failed" than "failed" companies.

\section{Research problem and research method}

\section{Definition of research problem}

In the study by Steyn-Bruwer and Hamman (2006) several deficiencies of previous studies in failure prediction were addressed. However, only RP was used as a technique in developing the models, while addressing these deficiencies. The main objective of this article is to compare the predictive accuracy of the MDA, LA, RP and NN against each other.

The secondary objective of this study is to compare the difference in predictive accuracy when the data is subdivided per economic phase (as done by Steyn-Bruwer and Hamman (2006)) as opposed to a subdivision of each 
year prior to failure as with previous research in this field.

After careful consideration of the significance of the cost of Type I and Type II errors in the literature survey, it became evident that a measure of "cost of failure" is required when assessing the various predictive techniques. In this regard, Muller (2008) proposes a new measure called the "Normalised Cost of Failure" (NCF). The NCF is essentially a sum of Type I and Type II errors where Type I errors are weighted by the additional cost of failure. Type I and Type II errors are defined as:

- Type I errors are incorrectly classifying "failed" companies as being healthy.

- Type II errors are incorrectly classifying “non-failed” companies as being financially distressed.

In terms of an investor or lending institution, a Type I error would result in the loss of the complete value of the investment in, or loan to the company in question. Conversely, a Type II error could potentially be the loss of the profit associated with the investment or loan made to the company. Zavgren (1985) stated that the cost ratio of Type I to Type II errors was in the range of $20: 1$ to 38:1. In 1977, Altman et al. (1977: 44), conducted an audit on several small regional banks and found that the cost ratio of a Type I error was 35 times greater than the cost of a Type II error.

As the Type I error can prove the most costly for the economy, the top limit for Type I to Type II errors of 38:1, as determined by Zavgren (1985), will be used in determining the NCF for each model. By introducing this measure, one can compare the cost of the predictive model developed by the different techniques.

\section{Research method}

The same data and variable selection used in the study of Steyn-Bruwer and Hamman (2006), serves as the basis for this article. This research therefore, is limited to a study of the financial distress of South African companies listed for at least three consecutive years on the JSE, with the exclusion of mining, financial and property companies. Financial ratios will be used as independent prediction variables for the time period between 1997 and 2002, while the time period from 2003 to 2006 will be used to track which of the above companies have actually "failed" or not.

In the work completed by Steyn-Bruwer and Hamman the population was subdivided into two economic periods recession and growth, while in this study the more conventional approach was adopted of dividing the data into " $x$ " number of years before failure. It is the authors' hypothesis that the subdivision of year before failure, rather than the economic phase, will have a greater impact on the predictability of financial distress.

A summary of the ratios portraying the independent variables are provided in Table 1 . These are the same independent variables that were used in the study of SteynBruwer and Hamman (2006) and they were selected inter alia to avoid brute empirism which is a weakness of many similar studies.

The focus on cash flow ratios is because a lack of cash flow is one of the most important causes of financial distress. Therefore, eight of the fifteen independent variables are cash flow ratios. Previous studies that used actual cash flow information (Schellenger \& Cross, 1994; Ward, 1994; Ward \& Foster, 1996; Sharma \& Iselin, 2003) substantiate the value of cash flow information in the development of models.

A company may succeed in surviving a year or two of negative cash flows, however, if a company cannot succeed in generating cash over a cumulative period of, for instance, three years, it may get into financial difficulty (Steyn, Hamman \& Smit, 2002). Therefore a combination of oneyear cash flow ratios as well as three-year cumulative cash flow ratios is used.

Accrual information does also contain valuable information on a possible financial distress situation. Therefore certain non-cash flow variables were also included (Steyn-Bruwer \& Hamman, 2006):

- Two profit ratios, for one year, as well as a cumulative three-year ratio, as they are indicative of the profit creating ability of the company and therefore the viability of the business plan.

- The size of the company is represented by the logarithm of the total assets which is normalised against the GDP deflator. The implication is that larger companies will probably have a greater chance of surviving than the smaller companies (Ohlson, 1980).

- The structure of the company as represented by four ratios. One ratio calculates the equity in relation to total liabilities; one that determines the ability of the company to pay its total debt from its current cash resources; a further ratio that calculates the size of the accounts receivable that must be financed by the company; and finally one ratio that determines the portion of total assets which consists of current assets. 
Table 1: Summary of independent variables used in the analysis

\begin{tabular}{|c|c|}
\hline Variable & Description of variable \\
\hline Log TA/GDP & $\begin{array}{l}\text { The logarithm of the total assets normalised to the GDP deflator. The size of the company must be taken into } \\
\text { consideration. }\end{array}$ \\
\hline LF:TL & Closing balance of cash divided by closing balance of total liabilities. \\
\hline $\mathrm{E}: \mathrm{TL}$ & Closing balance of equity divided by closing balance of total liabilities \\
\hline $\mathrm{AC}: \mathrm{S}$ & Closing balance of accounts receivable divided by sales for the year. \\
\hline WC:TA & Closing balance of working capital divided by total assets. \\
\hline $\mathrm{P}: \mathrm{S}$ & Profit for the year divided by the sales for the year. \\
\hline P3:S & Cumulative profit for the last three years divided by cumulative sales for the last three years. \\
\hline $\mathrm{CFO}: \mathrm{S}$ & Cash flow from operating activities divided by sales for the year. \\
\hline CFO3:S & Cumulative cash flow from operating activities for the last three years divided by cumulative sales for the last three years. \\
\hline CFO:TL & Cash flow from operating activities divided by total liabilities \\
\hline CFO3:TL & Cumulative cash flow from operating activities for the last three years divided by total liabilities. \\
\hline CFF:TL & Cash flow from financing activities divided by total liabilities. \\
\hline CFF3:TL & Cumulative cash flow from financing activities for the last three years divided by total liabilities \\
\hline CFI:TL & Cash flow from investing activities divided by total liabilities. \\
\hline CFI3:TL & Cumulative cash flow from investing activities for the last three years divided by total liabilities. \\
\hline
\end{tabular}

For each of the different predictive techniques (MDA, RP, $\mathrm{LA}$ and $\mathrm{NN}$ ) the following four tests were performed:

- $\quad$ Test 1 is between "non-failed” (648 observations) \& "failed" (148 observations) companies one year before failure.

- $\quad$ Test 2 is between "non-failed” (648 observations) \& "failed" (112 observations) companies two years before failure.

- Test 3 is between "non-failed” (648 observations) \& "failed" (96 observations) companies three years before failure.

- $\quad$ Test 4 is between "non-failed" (648 observations) \& "failed" (70 observations) companies four years before failure.

As the "non-failed" companies have no year of failure, these ratios were pooled across all years, similar to the method followed by Beaver, McNichols and Rhie (2005).

For the purposes of this study, the classify function within Matlab $^{\mathrm{TM}}$ is used to model the MDA equation; the mnrfit and mnval function in Matlab ${ }^{\mathrm{TM}}$ is used to develop the LA model, and the classregtree function in Matlab ${ }^{\mathrm{TM}}$ is used to develop the RP model. In terms of the $\mathrm{NN}$ model, the following philosophy and parameters were used to design the NN model:

- With regard to the input data, the first step in processing the data is to have the input data scaled. The input ratios are scaled into a range that is appropriate for the network. Usually the inputs are normalised linearly between 0 and 1 .

- $\quad$ The type of NN topology selected for this study was the feed-forward NN. According to Matlab ${ }^{\mathrm{TM}}$ (2007), the feed-forward NN topology is well suited to this type of prediction/classification problem. This is substantiated by the fact that the feed-forward $\mathrm{NN}$ provides accurate results with good processing speed. As such, the function used in Matlab ${ }^{\mathrm{TM}}$ is newff.

- In order to determine the optimum number of topology layers and neurons per layer, several iterations for each configuration were completed to determine which configuration provides the best results. Based on trial and error, it was decided to use a model with one hidden layer consisting of 15 neurons.

- $\quad$ Due to the fact that the prediction of financial distress is essentially a non-linear problem it was decided to use the log-sigmoid transfer function (logsig function in Matlab ${ }^{\mathrm{TM}}$ ) in the NN model.

- $\quad$ The Matlab ${ }^{\mathrm{TM}}$ training algorithm selected for this study was the trainlm algorithm. According to Matlab ${ }^{\mathrm{TM}} \mathrm{NN}$ user's guide, this algorithm is based on the Levenberg Marquardt algorithm and provides the best results for prediction applications and with acceptable processing speed.

For each of the four tests, as with SteynBruwer and Hamman (2006), two thirds of the input data were used to construct the model and one third of the "out of sample" inputs was used to validate the model. It is these validation results that are documented in the following section.

\section{Results of the models developed}

The prediction results of the validation sample for each of the different modelling techniques (tests 1 to 4 ) are presented in Table 2.

Here Table 2 shows that the overall prediction accuracy of 
MDA is 70,6\% for year 1 before failure, 66,4\% for year 2 before failure, $60,9 \%$ for year 3 before failure and $74,1 \%$ for year 4 before failure. The prediction accuracy for "failed" companies, which is the more important category, is $39,6 \%$ for year 1 before failure, 28,5\% for year 2 before failure, $34,2 \%$ for year 3 before failure and $41,3 \%$ for year 4 before failure. The "Normalised Cost of Failure" (NCF) as defined in this research is 1 262, 1 195, 1022 and 691 for years 1 , 2, 3 and 4 respectively before failure. The total prediction accuracy of $74,1 \%$ in the fourth year before failure is the best, with the $60,9 \%$ in the third year before failure, the worst. The prediction accuracy for the more important category of "failed" companies, is 39,6\%, 28,5\%, 34,2\% and $41,3 \%$ for years $1,2,3$ and 4 respectively before failure. Similar information for the other techniques can be read from Table 2.

The overall predictive accuracy (Table 2) for the NN is $81,9 \%, 85,4 \%, 85,5 \%$ and $86,6 \%$ (respectively for years 1 through 4 before failure). The results for the overall predictive accuracy for years 1,2 , and 3 are the best of the three techniques; however the LA model provides better predictive accuracy $(87,4 \%)$ for year 4 prior to failure.

Table 2: Results of the models developed by means of different techniques

\begin{tabular}{|c|c|c|c|c|c|c|c|c|c|c|c|c|c|c|c|c|}
\hline & \multicolumn{4}{|c|}{ MDA } & \multicolumn{4}{|c|}{ LA } & \multicolumn{4}{|c|}{ RP } & \multicolumn{4}{|c|}{ NN(ff) } \\
\hline & N yr1 & $\mathrm{N}$ yr2 & $\mathrm{N}$ yr3 & $\mathrm{N}$ yr4 & N yr1 & $\mathrm{N}$ yr2 & $\mathrm{N}$ yr3 & $\mathrm{N}$ yr4 & $\mathrm{N}$ yr1 & N yr2 & $\mathrm{N}$ yr3 & $\mathrm{N}$ yr4 & $\mathrm{N}$ yr1 & $\mathrm{N}$ yr2 & $\mathrm{N}$ yr3 & $\mathrm{N}$ yr4 \\
\hline $\begin{array}{l}\text { Failed correctly } \\
\text { predicted }\end{array}$ & 21 & 12 & 13 & 12 & 1 & 1 & 1 & 1 & 15 & 9 & 7 & 4 & 5 & 1 & 2 & 0 \\
\hline Type I error & 32 & 30 & 25 & 17 & 52 & 41 & 37 & 28 & 38 & 33 & 31 & 25 & 48 & 34 & 31 & 30 \\
\hline $\begin{array}{l}\text { Type II error } \\
\text { Non-failed }\end{array}$ & 46 & 55 & 72 & 45 & 4 & 2 & 1 & 2 & 35 & 25 & 22 & 22 & 0 & 3 & 5 & 2 \\
\hline $\begin{array}{l}\text { correctly } \\
\text { predicted }\end{array}$ & 166 & 156 & 138 & 165 & 208 & 209 & 209 & 208 & 177 & 186 & 188 & 188 & 212 & 215 & 210 & 207 \\
\hline Total & 265 & 253 & 248 & 239 & 265 & 253 & 248 & 239 & 265 & 253 & 248 & 239 & 265 & 253 & 248 & 239 \\
\hline $\begin{array}{l}\text { Incorrectly } \\
\text { predicted in total }\end{array}$ & 78 & 85 & 97 & 62 & 56 & 43 & 38 & 30 & 73 & 58 & 53 & 47 & 48 & 37 & 36 & 32 \\
\hline $\begin{array}{l}\text { Correctly } \\
\text { predicted in total }\end{array}$ & 187 & 168 & 151 & 177 & 209 & 210 & 210 & 209 & 192 & 195 & 195 & 192 & 217 & 216 & 212 & 207 \\
\hline NCF (38:1) & 1262 & 1195 & 1022 & 6991 & 1980 & 1560 & 1407 & 1066 & 1479 & 1279 & 1200 & 972 & 1824 & 1295 & 1183 & 1142 \\
\hline & \% yr1 & \% yr2 & $\%$ yr3 & $\%$ yr4 & \% yr1 & \% yr2 & $\%$ yr3 & $\%$ yr4 & \% yr1 & \% yr2 & \% yr3 & \% yr4 & $\%$ yr1 & \% yr2 & \% yr3 & $\%$ yr4 \\
\hline $\begin{array}{l}\text { \% of failed } \\
\text { companies } \\
\text { correctly } \\
\text { predicted }\end{array}$ & $39,6 \%$ & $28,5 \%$ & $34,2 \%$ & $41,3 \%$ & $1,9 \%$ & $2,4 \%$ & $2,6 \%$ & $3,4 \%$ & $28,3 \%$ & $21,4 \%$ & $18,4 \%$ & $13,7 \%$ & $9,4 \%$ & $2,9 \%$ & $6,1 \%$ & $0 \%$ \\
\hline $\begin{array}{l}\text { \% of non-failed } \\
\text { companies } \\
\text { correctly } \\
\text { predicted }\end{array}$ & $78,3 \%$ & $73,9 \%$ & $65,7 \%$ & $78,6 \%$ & $98,1 \%$ & $99,1 \%$ & $99,5 \%$ & $99,0 \%$ & $83,5 \%$ & $88,2 \%$ & $89,5 \%$ & $89,5 \%$ & $100 \%$ & $98,6 \%$ & $97,7 \%$ & $99,0 \%$ \\
\hline $\begin{array}{l}\% \text { of total } \\
\text { incorrectly } \\
\text { predicted }\end{array}$ & $29,4 \%$ & $33,6 \%$ & $39,1 \%$ & $25,9 \%$ & $21,1 \%$ & $17,0 \%$ & $15,3 \%$ & $12,6 \%$ & $27,5 \%$ & $22,9 \%$ & $21,4 \%$ & $19,7 \%$ & $18,1 \%$ & $14,6 \%$ & $14,5 \%$ & $13,4 \%$ \\
\hline $\begin{array}{l}\% \text { of total } \\
\text { correctly } \\
\text { predicted }\end{array}$ & $70,6 \%$ & $66,4 \%$ & $60,9 \%$ & $74,1 \%$ & $78,9 \%$ & $83,0 \%$ & $84,7 \%$ & $87,4 \%$ & $72,5 \%$ & $77,1 \%$ & $78,6 \%$ & $80,3 \%$ & $81,9 \%$ & $85,4 \%$ & $85,5 \%$ & $86,6 \%$ \\
\hline
\end{tabular}

Furthermore, the prediction accuracy of both NN and LA for "failed" companies is very low, which results in high NCF ratios for all four years prior to failure. Based on these high NCF ratios, it is important to note that these analysis techniques have major cost implications to financial investors and lending institutions.

When focussing on the "failed" category, MDA has the best results of the techniques, with the best prediction accuracy, as well as the lowest NCF ratio.

The results of the table appear to be consistent with other research where the overall predictive accuracy deteriorates as one moves further away from the year before financial distress, however the results from year 4 appear to be inconsistent with this theory.
The average predictive accuracies for each technique (for the four years prior to failure) are provided in Table 3 .

From Table 3 it is evident that the NN (84,8\%), closely followed by LA (83,5\%), provides the best overall predictive accuracy for all the techniques. A further observation is that MDA $(14,5)$ followed by $\mathrm{RP}(8,8)$, correctly predict the most number of "failed" companies and therefore have the lowest NCF figures. Consequently, the NCF figure for LA and NN are the worst due to the poor performance in correctly predicting the number of "failed" companies.

As such, the main objective of this research has been achieved by showing that each modelling technique produces different prediction accuracies. 
Table 3: Average predictive accuracy for each different technique

\begin{tabular}{|c|c|c|c|c|}
\hline & MDA & LA & $\mathbf{R P}$ & $\mathbf{N N}(\mathbf{f f})$ \\
\hline & $\mathbf{N}$ & $\mathbf{N}$ & $\mathbf{N}$ & $\mathbf{N}$ \\
\hline Failed correctly predicted & 14,5 & 1,0 & 8,8 & 2,0 \\
\hline Type I error & 26,0 & 39,5 & 31,8 & 35,8 \\
\hline Type II error & 54,5 & 2,3 & 26,0 & 2,5 \\
\hline Non-failed correctly predicted & 156,3 & 208,5 & 184,8 & 211,0 \\
\hline Total & 251,3 & 251,3 & 251,3 & 251,3 \\
\hline Incorrectly predicted in total & 80,5 & 41,8 & 57,8 & 38,3 \\
\hline Correctly predicted in total & 170,8 & 209,5 & 193,5 & 213,0 \\
\hline \multirow[t]{2}{*}{ NCF (38:1) } & 1042,5 & 1503,3 & 1232,5 & 1361,0 \\
\hline & $\%$ & $\%$ & $\%$ & $\%$ \\
\hline$\%$ of failed companies correctly predicted & 35,9 & 2,6 & 20,5 & 4,6 \\
\hline \% of non-failed companies correctly predicted & 74,1 & 98,9 & 87,7 & 98,8 \\
\hline$\%$ of total incorrectly predicted & 32,0 & 16,5 & 22,9 & 15,2 \\
\hline$\%$ of total correctly predicted & 68,0 & 83,5 & 77,1 & 84,8 \\
\hline
\end{tabular}

In order to conclude on the subordinate research objective, the results achieved in this study for RP are compared against the results achieved by Steyn-Bruwer and Hamman (2006) (see Table 4). The average results for the RP models developed in this study $(77,1 \%)$ prove to be better than that of the Steyn-Bruwer and Hamman study (combined model 65,9\%). However, the Steyn-Bruwer and Hamman combined model has far better results in predicting "failed" companies accurately (66,9\% versus 20,5\%). As the "failed" category is the more important category regarding costs to the economy, the importance of the results for this category cannot be underestimated.

The composition of the validation samples in these two studies differs, because of (1) the number of observations included, and (2) the proportion of "failed" to "non-failed" companies that is materially higher in the SteynBruwer and Hamman study than in the current study. In the sample where the proportion of "non-failed" companies is higher, the NCF will most probably be higher, just because of the difference in the number of companies. The NCF ratio therefore loses some of its value as a comparison as such can not be done, considering these differences. In trying to equalise the measure, the NCF was calculated "per observation" in the sample. This will then represent a cost per company and not the total cost. For the average RP models, this NCF per observation is 4,9 versus 5,2 for the Steyn-Bruwer and Hamman combined model. This indicates that the prediction accuracy might be slightly better if the data is categorised according to year before failure and not per economic phase. This finding confirms the subordinate research problem.

Table 4: Recursive partitioning results for Steyn-Bruwer and Hamman

\begin{tabular}{|c|c|c|c|c|}
\hline & \multirow{2}{*}{$\begin{array}{c}\text { This study } \\
\text { Average RP } \\
\text { N }\end{array}$} & \multicolumn{3}{|c|}{ Steyn-Bruwer \& Hamman } \\
\hline & & $\begin{array}{c}\text { Combined } \\
\mathbf{N}\end{array}$ & $\begin{array}{c}\text { Recession } \\
\mathbf{N}\end{array}$ & $\begin{array}{c}\text { Growth } \\
\mathbf{N}\end{array}$ \\
\hline Failed correctly predicted & 8,8 & 95 & 48 & 36 \\
\hline Type I error & 31,8 & 47 & 31 & 27 \\
\hline Type II error & 26,0 & 75 & 24 & 28 \\
\hline Non-failed correctly predicted & 184,8 & 141 & 88 & 76 \\
\hline Total & 251,3 & 358 & 191 & 167 \\
\hline Incorrectly predicted in total & 57,8 & 122 & 55 & 55 \\
\hline Correctly predicted in total & 193,5 & 236 & 136 & 112 \\
\hline Proportion of "failed” to “non-failed” (\%) & 16,1 & 39,7 & 41,4 & 37,7 \\
\hline NCF (38:1) & 1232,5 & 1861,0 & 1202,0 & 1054,0 \\
\hline \multirow[t]{2}{*}{ NCF per observation } & 4,9 & 5,2 & 6,3 & 6,3 \\
\hline & $\%$ & $\%$ & $\%$ & $\%$ \\
\hline \% of failed companies correctly predicted & 20,5 & 66,9 & 60,8 & 57,1 \\
\hline \% of non-failed companies correctly predicted & 87,7 & 65,3 & 78,6 & 73,1 \\
\hline \% of total incorrectly predicted & 22,9 & 34,1 & 28,8 & 32,9 \\
\hline$\%$ of total correctly predicted & 77,1 & 65,9 & 71,2 & 67,1 \\
\hline
\end{tabular}




\section{Conclusion}

The first conclusion drawn from the literature surveyed, was the fact that there is very little consensus on any of the major issues within the field of study. Secondly, the literature does not readily take cognisance of the number of Type I and Type II errors made when evaluating each predictive technique. As a consequence this study defines a term called the "Normalised Cost of Failure" (NCF), which takes into account the fact that a Type I error typically costs 20 to 38 times that of a Type II error. This new variable has added significant value when evaluating the different analysis techniques.

The research completed by Steyn-Bruwer and Hamman (2006) on the South Africa JSE formed the departure point for this research. The difference between the data used by Steyn-Bruwer and Hamman (2006) and the data used in this research, is that this research subdivided the data in years before failure, while Steyn-Bruwer and Hamman (2006) subdivided the data according to economic phases.

Based on this data, a comparison of each of the different analysis techniques MDA, RP, LA and NN was made and documented.

The main objective of this research was met by showing that each of the different modelling techniques produced different predictive accuracies. Here MDA and RP techniques correctly predicted the most number of "failed" companies and consequently had the lowest NCF. The research also showed that LA and NN provided the best overall predictive accuracy, but conversely had the highest NCF ratio.

The subordinate objective of the research was to compare the difference in predictive accuracies when the data is subdivided per economic period, as done by Steyn-Bruwer and Hamman (2006), as opposed to a subdivision of each year prior to failure as with the conventional literature. This work shows that using the year before failure as a subdivision, rather than the economic period as a subdivision, provides somewhat better predictive accuracy.

Finally, the research proposes that the predictive strengths of the four different modelling techniques are combined to attain a better overall predictive methodology.

\section{Acknowledgements}

The authors would like to sincerely thank and acknowledge Dean Redelinghuys and Optimun Solutions for their assistance and support with Matlab ${ }^{\mathrm{TM}}$ software during the course of this research.

\section{References}

Altman, E.I. 1968. 'Financial ratios, discriminant analysis and the prediction of corporate bankruptcy', The Journal of Finance, 23(4): 589-609.
Altman, E. 1993. Corporate financial distress and bankruptcy. $2^{\text {nd }}$ Edition. New York: John Wiley.

Altman, E.I. 2000. 'Predicting financial distress of companies revisiting the z-score and zeta model'. [online] URL: $\quad$ http://pages.stern.nyu.edu/ ealtman/Zscores.pdf. Accessed 30 October 2007.

Altman, E., Haldeman, R.G. \& Narayanan, P. 1977. 'Zeta Analysis: A new model to identifying bankruptcy risk of corporations', Journal of Banking and Finance. 1:29-54.

Agarwal, V. \& Taffler, R. 2007. 'Comparing the performance of market-based and accounting based bankruptcy prediction models'. [online] URL: http://www.crc.man.ed.ac.uk/publications/papers/workingpa pers/workingpaper07-6.pdf. Accessed 30 October 2007.

Arron, J. \& Sandler, M. 1995. 'The use of Neural networks in predicting company failure', De Ratione, 8(2): 57-58.

Aziz, A.M. \& Lawson, G.H. 1989. 'Cash flow reporting and financial distress models: Testing of hypotheses', The Journal of the Financial Management Association, 18(1):55-63.

Aziz, A.M. \& Humayon, A.D. 2006. 'Predicting corporate bankruptcy: Where we stand?', Journal of Corporate Governance, 6(1): 18-33.

Back, B., Laitinen, T., Sere, K. \& Wezel, M.V. 1996. Choosing bankruptcy predictors using discriminant analysis, Logit analysis and genetic algorithms. Technical Report no.40, Turku Centre for Computer Science, Turku.

Balcaen, S. \& Ooghe, H. 2006. '35 years of studies on business failure: An overview of the classic statistical methodologies and their related problems', The British Accounting Review, 38(1):63-93.

Beaver, W. H. 1966. 'Financial ratios as predictors of failure', Journal of Accounting Research, 4(3):71-111.

Beaver, W.H., McNichols, M.F. \& Rhie, J. 2005. 'Have financial statements become less informative? Evidence from the ability of financial ratios to predict bankruptcy', Review of Accounting Studies, 10(1):93-122.

Court, P.W. \& Radloff, S.E. 1990. 'A comparison of multivariate dicriminant and logistic analysis in the prediction of corporate failure in South Africa', De Ratione, 4(2):11-15.

Cybinski, P. 2001. 'Description, explanation, prediction the evolution of bankruptcy studies?', Managerial Finance, 27(4): 29-44.

Deakin, E. B. 1972. 'A discriminant analysis of predictors of business failure', Journal of Accounting Research, 10(1):167-179. 
Foster, G. 1986. Financial statement analysis. $2^{\text {nd }}$ Edition. Prentice-Hall International Editions.

Grice, J.S. \& Ingram, R.W. 2001. 'Tests of the generalizability of Altman's bankruptcy prediction model', Journal of Business Research, 54(1):53-61.

Kuruppu, N., Laswad, F. \& Oyelere, P. 2003. 'The efficacy of liquidation and bankruptcy prediction models for assessing going concern', Managerial Auditing Journal, 18(6/7):577-590.

Matlab $^{\mathrm{TM}}$. 2007. 'Neural network toolbox 5: Users guide’.[online] URL:

http://www.mathworks.com/access/helpdesk/help/toolbox/n net. Accessed 29 September 2007.

Muller, G.H. 2008. 'Development of a model to predict financial distress of companies listed on the JSE.' Research report, University of Stellenbosch Business School.

Ohlson, J.A. 1980. 'Financial ratios and the probabilistic prediction of bankruptcy', Journal of Accounting Research, 18(1):109-131

Pompe, P.P.M. \& Bilderbeek, J. 2005. 'The prediction of bankruptcy of small- and medium-sized industrial firms', Journal of Business Venturing, 20(6):847-868.

Rees, B. 1995. Financial analysis. Englewood Cliffs: Hertfordshire, Prentice Hill.

Schellenger, M. \& Cross, J.N. 1994. 'FASB 95, cash flow and bankruptcy', Journal of Economics and Finance, 18(3):261-274.

Sharma, D.S. \& Iselin, E.R. 2003. 'The relative relevance of cash flow and accrual information for solvency assessments: A multi-method approach', Journal of Business Finance and Accounting, 30(7 \& 8):1115-1140.

Statistica $^{\mathrm{TM}}$. 2008. 'Discriminant function analysis'. [online] URL: $\quad$ http://www.statsoft.com/textbook/stdiscan.html. Accessed: 20 January 2008.

Steyn-Bruwer, B.W. \& Hamman, W.D. 2006. 'Company failure in South Africa: Classification and prediction by means of Recursive partitioning', South African Journal of Business Management, 34(4):1-12.

Steyn, B.W., Hamman, W.D. \& Smit, E.vdM. 2002. 'The danger of high growth combined with a large non-cash working capital base - a descriptive analysis', South African Journal of Business Management, 33(1):41-47.

Taffler, R.J. 1982. 'Forecasting company failure in the UK using discriminant analysis and financial ratio data', Journal of Royal Statistical Society, 145(3):342-358.

Ward, T.J. 1994. 'Cash flow information and the prediction of financially distressed mining, oil and gas firms: A comparative study', Journal of Applied Business Research, 10(3):78-86.

Ward, T.J. \& Foster, B.P. 1996. 'An empirical analysis of Thomas's financial accounting allocation fallacy theory in a financial distress context', Accounting and Business Research, 26(2):137-152.

Wikipedia. 2008. 'Financial distress'. [online] URL: http://encyclopedia.thefreedictionary.com/Financial+distress Accessed 29 January 2008.

Zavgren, C.V. 1985. 'Assessing the vulnerability to failure of American industrial firms: A logistic analysis', Journal of Business Finance and Accounting. 12(1):19-45.

Zirilli, J.S. 1997. Financial prediction using neural networks. London: Thomson Computer Press. 